\title{
АНАЛИЗ ВОЛОС И ПИТЬЕВОЙ ВОДЫ ЖИТЕЛЕЙ РАЗНЫХ ЗОН РЕСПУБЛИКИ ДАГЕСТАН
}

\section{HAIR ANALYSIS OF RESIDENTS OF DIFFERENT ZONES OF THE REPUBLIC OF DAGESTAN}

\author{
K. Alieva \\ P. Daniyalova \\ T. Abdulmutalimova \\ A. Magomedov \\ A. Zaynudinova \\ R. Nasrulaeva
}

Summary. This article analyzes the microelement composition of the hair of the population of two territories: the Northern arid part (Babayurtovsky district) of the Republic of Dagestan and the quality of drinking water supply. An increased content of toxic arsenic was found in the hair of the population of Babayurt district, which is associated with its content in artesian waters used by residents as a drinking source. In the hair of residents of Tabasaran district, an imbalance of zinc and copper and a slight increase in the permissible values of lead were detected, which is most likely due to the widespread use of chemicals and poisons in agriculture.

Keywords: body, environment, toxic substances, hair analysis.
Алиева Камилла Гаджимурадовна

К.б.н., доцент, Дагестанский государственный медицинский университет kamilla.1974@mail.ru

Даниялова Патимат Митхатовна

К.б.н., доцент, Дагестанский государственный медицинский университет zoom_zoom_2213@mail.ru

Абдулмуталимова Тамила Омариевна К.б.н., ФГБУН «Институт геологии Дагестанского научного чентра Российской академии наук»; ФГБУН «Институт проблем геотермии Дагестанского научного чентра Российской академии наук» tamila4@mail.ru

Магомедов Абдурахман Маллаевич Д.б.н., профессор, Дагестанский государственный медицинский университет abdurahman57@mail.ru

Зайнудинова Асият Изамутдиновна Дагестанский государственный медицинский университет asiyat232001@icloud.com

Насрулаева Равзанат Афендиевна Дагестанский государственный медицинский университет

nasrulaeva_r@mail.ru

Аннотация. Данная статья посвящена анализу микроэлементного состава волос населения двух территорий: северной засушливой части (Бабаюртовский район) Республики Дагестана и качеству питьевого снабжения. Обнаружено увеличенное содержание токсичного мышьяка в волосах населения Бабаюртовского района, что связано с содержанием его в артезианских водах, используемых жителями в качестве питьевого источника. В волосах жителей Табасаранского района выявлен дисбаланс цинка и меди и незначительное повышение допустимых значений свинца, которое скорее всего связано с широким применением химикатов и ядов в сельском хозяйстве.

Ключевые слова: организм, окружающая среда, токсичные вещества, анализ волос.

применение биологических маркеров, которые позволяют определить наличие этого вещества в тканях человека и дозу, полученную от всех источников поступления вещества. Данные биомониторинга показывают содержание вредоносных веществ в организме. Эти данные являются актуальным показателем для оценки воздействия на здоровье, для таких загрязнителей, как мышьяк, ртуть, никель, которые входят в список ВОЗ токсикантов. 
Биоматериалом, используемым в медико-биологических и экологических исследованиях, являются волосы, так как они преимущественно информативный биосубстрат.

\section{Объекты и мето исслеАования}

Был проведён качественный анализ биоматериала (волос) и питьевой воды поселениях Бабаюртовского и Табасаранского районов, отличающихся природно-климатическими особенностями.

Предметами исследований в поселениях Бабаюртовского и Табасаранского районов, где жители пользуются подземными водами для хозяйства и питьевого назначения были:

- образцы питьевой воды

- образцы биоматериалов жителей, которые проживают в поселениях.

Образцы питьевой воды и биоматериалов собирались в промытый сосуд объемом 0,5 л из полимера, предназначенного для контакта с пищевыми продуктами. Прежде сосуды ополаскивались водой, подлежащей анализу, около трёх раз. Затем заполнялись ею.

Из каждого источника брали по 2 пробы, одну из них консервировали $\mathrm{HCl}$ до $\mathrm{pH}$ 1-2. Для защиты от нагревания летом, и замораживания зимой, бутылки с водой ставили в теплоизолированную тару.

К пробе волы прилагались документы с указанием:

- места отбора: район, поселение

- время и дата отбора: число, год, месяц

Для проведения следующего анализа воды, образцы поставлялись 2 дня в лабораторию Дагестанского научного центра Российской Академии Наук с современными приборами. Изучение питьевых вод проводились на стационарных аналитических установках в лабораторных условиях с использованием методик измерений. Содержание $\mathrm{Ca}$ и $\mathrm{Mg}$ в водах определяли трилонометрическим методом. Биокарбонатов- титрованием $\mathrm{HCl}$.

$\mathrm{Fe}, \mathrm{Cu}, \mathrm{Zn}$ - атомно-адсорбционным методом. Измерение содержания мышьяка проводили атомно-абсорбционным методом. Содержащиеся в этих источниках анионы определяли методом электрокапиллярного анализа. Значения, которые были получены в ходе анализа сравнили с нормативными величинами.

Для проведения анализа нужна прядь волос длиной 3-5 см. Волосы постригались в 2-3 разных местах с за- тылочной части, ближе к шее и далее соединялись в пучок, толщиной 2-3мм. Волосы должны быть чистыми, без лака и геля. Для хранения использовались бумажные конверты. Специальных условий хранения не требовалось.

Подготовку проб волос на анализ проводили согласно МУК 4.1.776-99 «Методы контроля. Установление содержания железа, цинка, никеля, медиа в волосах методом атомной абсорбции». Образцы волос выдерживали в смеси диэтилового эфира и этилового спирта в соотношении 1:1, промывали, высушивали. Очищенные пробы хранили в эксикаторе. Для растворения волос использовали смесь азотной кислоты и перекиси водорода в соотношении 3:1, с добавлением - $\mathrm{PdNO}_{3}$.

Данные качественного анализа питьевых вод Бабаюртовского и Табасаранского районов приведены в таблицах 1 и 2. Жирным шрифтом выделены значения, отклоняющиеся от нормативных величин.

Во всех исследованных образцах волос жителей Табасаранского района содержание меди колеблется в интервале 0,4-8,6 мкг/г, при этом для образцов 1,2, 3, $5,6,8,9,10,11,12$ оно ниже физиологической нормы. Обнаружен дисбаланс по цинку. У всех представленных образцов оно также ниже физиологической нормы. Дефицит цинка может приводить к накоплению $\mathrm{Fe}$, $\mathrm{Cu}, \mathrm{Cd}$

Наименьшее количество свинца характерно для образца 9, многократное превышение среднестатистических показателей в образцах 4, 12. У всех исследуемых людей значения содержания $\mathrm{Hg}$ и $\mathrm{Cd}$ в волосах находится в пределах фоновых содержаний.

Допустимой причиной дисбаланса микроэлементного статуса волос жителей Табасаранского района может являться применение минеральных удобрений в сельском хозяйстве. Большая часть вредоносных химических веществ из почвы добавляется в водное течение, вовлекается в биологический круговорот растениями и попадает с продуктами в организм человека.

Повышенное содержание мышьяка в питьевых водах Бабаюртовского района вызвано особенностями строения поселения Северного Дагестана, гидрохимическими свойствами вод артезианского бассейна и климатом, способствующим повышению минерализации и концентрации токсичных веществ.

Для подтверждения накопления мышьяка в организме жителей Северного Дагестана, нужно проведение более точных исследований с использованием биомониторинга. 
Таблица 1. Результаты анализов питьевых вод поселений Табасаранского района

\begin{tabular}{|c|c|c|c|c|c|c|c|c|c|c|c|c|c|}
\hline $\begin{array}{l}\text { Насе- } \\
\text { ленные } \\
\text { пункты }\end{array}$ & $\mathrm{Na}^{+}$ & $\mathrm{Ca}^{+2}$ & $\mathrm{Mg}^{+2}$ & $\mathrm{Fe}_{\mathrm{o} 6}$ & $F^{-}$ & $\begin{array}{l}\mathrm{Cl}^{-} \\
(350)\end{array}$ & $\begin{array}{l}\mathrm{NO}_{3}{ }^{-} \\
(45)\end{array}$ & $\mathrm{SO}_{4}^{-}$ & $\mathrm{HCO}_{3}$ & As & $\begin{array}{l}\text { Жестк. } \\
(7,0)\end{array}$ & $\begin{array}{l}\text { Минер. } \\
\text { 1000мг/л }\end{array}$ & $\begin{array}{l}\text { pH } \\
(6-8)\end{array}$ \\
\hline Пилиг & & & & & & 75,6 & 47,7 & 82,3 & 589,6 & - & 8,6 & 1063,9 & 7,7 \\
\hline Куркак & & & & & & 1,6 & 20,4 & 17,2 & 420,9 & - & 6,1 & 607,1 & 7,6 \\
\hline Хурик & 34 & 70,4 & 14,9 & 0,03 & 0,4 & 2,3 & 14,6 & 8,4 & 347,7 & - & 4,7 & 492,7 & 7,6 \\
\hline Цантил & 40 & 102 & 12,2 & 0,04 & 0,4 & 1,6 & 20,4 & $\begin{array}{l}\mathrm{Na}^{+} \\
200\end{array}$ & $\mathrm{Ca}^{+2}$ & $\mathbf{M g}^{+2}$ & $\begin{array}{l}\mathrm{Fe}_{\text {оби }} \\
(\text { (ПК 0,3) }\end{array}$ & \begin{tabular}{|l}
$\mathbf{F}^{-}$ \\
$(1.5)$
\end{tabular} & 7,6 \\
\hline Чулат & 75 & 105,2 & 24,3 & 0,05 & 0,6 & 17,6 & 21,2 & 129,7 & 96 & 46,2 & 0,04 & 0,5 & 7,6 \\
\hline Диргил & 30 & 62,3 & 17 & 0,04 & 0,7 & 1,7 & 13,1 & 36,1 & 92,2 & 18,2 & 0,05 & 0,7 & 7,6 \\
\hline Хулаг & 43 & 16,2 & 8,5 & 0,01 & 0,5 & 0,6 & 8,9 & 9,7 & 183 & - & 1,5 & 270,1 & 7,4 \\
\hline Татиль & 35 & 120 & 32,8 & 0,06 & 0,5 & 22,1 & 57,8 & 64,4 & 445,2 & - & 8,7 & 777,7 & 7,7 \\
\hline Цанак & 31 & 85 & 36,5 & 0,05 & 0,6 & 5,9 & 24 & 35 & 445,3 & - & 7,25 & 663,7 & 7,8 \\
\hline Ерси & 67 & 98 & 22,2 & 0,06 & 0,7 & 3,2 & 21,6 & 20,3 & 524,9 & - & 6.85 & 777 & 7,7 \\
\hline
\end{tabular}

Таблица 2. Результаты анализов питьевых вод поселений Бабаюртовского района

\begin{tabular}{|c|c|c|c|c|c|c|c|c|c|c|c|c|c|}
\hline $\begin{array}{l}\text { Населенные } \\
\text { пункты }\end{array}$ & $\mathrm{Na}^{+}$ & $\mathrm{Ca}^{+2}$ & $\mathrm{Mg}^{+2}$ & $\mathrm{Fe}_{\mathrm{o6}}$ & $F^{-}$ & $\mathrm{Cl}^{-}$ & $\mathrm{NO}_{3}{ }^{-}$ & $\mathrm{SO}_{4}^{-2}$ & $\mathrm{HCO}_{3}$ & As & $\begin{array}{l}\text { Жестк. } \\
(7,0)\end{array}$ & $\begin{array}{l}\text { Минер. } \\
1000 \mathrm{Mr/л}\end{array}$ & $\begin{array}{l}\mathrm{pH} \\
(6-8)\end{array}$ \\
\hline Львовское 1 & 132,3 & 24,45 & 10,09 & - & 0,25 & 59,90 & - & 109,6 & 244 & 30,34 & 2,05 & 561 & 7,7 \\
\hline г.Бабаюрт & 240 & 14,53 & 4,99 & - & 0,25 & 41,13 & - & 117,80 & 485 & 65,88 & 1,14 & 795 & 8,14 \\
\hline с.Геметюбе & 243.1 & 15,03 & 5,47 & - & 0,40 & 50,53 & - & 160,80 & 427 & 21,11 & 1,20 & 750 & 8,26 \\
\hline Татаюрт & 240,6 & 10,42 & 7,66 & - & 0,5 & 58,86 & - & 88,9 & 494,1 & 58,6 & 1,15 & 827 & 7,9 \\
\hline Камбулат & 270,3 & 46,80 & 17,73 & - & 0,8 & 97,50 & - & 232,8 & 485 & 42,25 & 3,8 & 629 & 7,82 \\
\hline Хамзаюрт & 305,2 & 44,08 & 14,33 & - & 0,72 & 17,73 & - & 392,4 & 280,6 & 4,4 & 3,38 & 369 & 7,10 \\
\hline Львовское 5 & 148,5 & 47,09 & 26,1 & - & - & 64,80 & - & 45,8 & 451,4 & 14,5 & 4,5 & 534 & 6,14 \\
\hline ЛЬВОВСК & 273,8 & 11,02 & 12,5 & - & - & 30,65 & - & 12 & 664,9 & 271,6 & 1,58 & 608 & 8,03 \\
\hline $\begin{array}{l}\text { СКв.1. (у Новой } \\
\text { Косы) }\end{array}$ & 312 & 4,8 & 8,2 & - & - & 11,13 & - & 36 & 640,5 & 158,3 & 1,07 & 679 & 8,35 \\
\hline $\begin{array}{l}\text { Скв.м/р-на } \\
\text { «Водник» }\end{array}$ & 233,1 & 3,8 & 8,14 & - & - & 39 & - & 104,2 & 555,1 & 202 & 0,86 & 780,5 & 7,98 \\
\hline
\end{tabular}

Таблица 3. Содержание веществ в волосах жителей Табасаранского района

\begin{tabular}{|l|l|l|l|l|l|l|}
\hline & $\mathbf{C u}$ & $\mathrm{Pb}$ & $\mathbf{C d}$ & $\mathbf{Z n}$ & As & Hg \\
\hline 1 & 4.0 & 2.8 & 0.0060 & 22.1 & 0.0035 & 0.36 \\
\hline 2 & 3.4 & 4.4 & 0.0100 & 11.8 & 0.0003 & 0.13 \\
\hline 3 & 1.8 & 2.3 & 0.0035 & 44.7 & 0 & 0 \\
\hline 5 & 7.1 & 25.2 & 0.0054 & 12.9 & 0 & 0.29 \\
\hline 6 & 3.8 & 2.3 & 0.0073 & 2.0 & 0 & 0.78 \\
\hline 7 & 1.5 & 1.2 & 0.0033 & 7.2 & 0 & 0.21 \\
\hline 8 & 8.6 & 1.4 & 0.0081 & 8.9 & 0 & 0.054 \\
\hline 9 & 1.8 & 1.8 & 0.0087 & 14.0 & 0 & 0.14 \\
\hline 10 & 0.6 & 0.5 & 0.0016 & 15.1 & 0.022 & 0.063 \\
\hline 11 & 1.7 & 0.8 & 0.0085 & 5.9 & 0 & 0.12 \\
\hline 12 & 5.7 & 1.6 & 0.0174 & 12.5 & 0 & 0.12 \\
\hline Допустимые уровни & $6.8-30$ & $0.20-5.00$ & $0.35-2.43$ & $120-250$ & $0,01-1.0$ & 0.045 \\
\hline
\end{tabular}


Таблица 4. Содержание мышьяка в волосах жителей Бабаюртовского района

\begin{tabular}{|l|l|l|}
\hline № /№ & Концентрация As в воде (мг/л) & Аs в волосах (мкг/г) \\
\hline 1 & 0,132 & 0,330 \\
\hline 2 & 0,142 & 0,500 \\
\hline 3 & 0,152 & 0,300 \\
\hline 4 & 0,162 & 0,410 \\
\hline 6 & 0,172 & 0,300 \\
\hline 7 & 0,182 & 0,500 \\
\hline 8 & 0,192 & 0,300 \\
\hline 9 & 0,2 & 0,100 \\
\hline 10 & 0,202 & 0,452 \\
\hline 11 & 0,21 & 0,700 \\
\hline 12 & 0,212 & 0,300 \\
\hline 13 & 0,22 & 0,470 \\
\hline 14 & 0,222 & 0,330 \\
\hline 15 & 0,227 & 0,500 \\
\hline
\end{tabular}

В ходе данного исследования различия по содержанию исследуемых элементов среди мужского и женского населения выявлены не были.

\section{Результаты}

анализов питьевых вод в Бабаюртовском районе Дагестана говорят о несоответствии качества воды по содержанию мышьяка. Дальнейшее пользование этими водами для питья требует изучения с целью воздействия на здоровье человека и окружающую среду и разработку методов очистки вод от мышьяка перед использованием.

Качество питьевой воды в Табасаранском районе соответствует нормативным требованиям, но нудно обратить внимание на содержание некоторых веществ ниже филологической нормы, что может быть причиной различных патологий. Метод биомониторинга позволил выявить изменения в микроэлементном статусе волос жителей.

\section{ЛИТЕРАТУРА}

1. Абдулмуталимова Т.0., Курбанова Л. М., Гусейнова А. Ш., Курбанисмаилова А. С. Особенности питьевого водоснабжения в аридной зоне Республики Дагестан // Аридные экосистемы. Т. 23, № 1(70) - 2017 г.- С. 93-97

2. Абдурахманов Г.М., Гасангаджиева А. Г., Габибова П. И., Махачкала Эколого-географическая обусловленность и прогноз заболеваемости злокачественными новообразованиями населения в РД.// 2009, с. 20-21.

3. Курбанова Л.М., Самедов Ш. Г., Газалиев И. М., Абдулмуталимова Т. О. Мышьяк в подземных водах Северо-Дагестанского артезианского бассейна // Геохимия. - 2013. - № 3.- С. 262-264.

4. Любченко П. Н. Скрининговые методы для выявления групп повышенного риска среди рабочих, контактирующих с токсичными химическими элементами: методические рекомендации МР 7-2/23-3129

5. Скальный А. В. Эколого-физиологическое обоснование эффективности использования макро- и микроэлементов при нарушениях гомеостаза у обследуемых из различных климато-географических регионов: Дис.д-ра мед.наук. М., 2000. 361 с.;

6. Ревич Б. А. Биомониторинг металлов в организме человека. Микроэлементы в медицине. 2005.Т.6.№ 4. С. 11-16.

7. Содержание меди и цинка в волосах населения башкирского Зауралья // Молодежный научный форум: Естественные и медицинские науки: электр. сб. ст. по материалам XX студ. междунар. заочной науч.-практ. конф.— М.: «МLH0».— 2015 —№ 1(19) / [Электронный ресурс] — Режим доступа.— URL: https://nauchforum.ru/archive/MNF_nature/1(19).pdf.

8. ГОСТ Р 51593-2000 Вода питьевая. Отбор проб. [Электронный ресурс] / Информационный портал «0храна труда России». Режим доступа: httр:// ohranatruda.ru/ot_biblio/normativ/data_n orтay/11/11182/

9. ГОСТ 31957-2012 Вода. Методы определения щелочности и массовой концентрации карбонатов и гидрокарбонатов. [Электронный ресурс] / Режим доступа: http://www.internet-law.ru/gosts/gost/56411/. 
10. ГоСТ 30178-96 Атомно-абсорбционный метод определения токсичных элементов. [Электронный ресурс] / Режим доступа: http://www. internet-law.ru/ gosts/gost/9123/

11. ПНД Ф 14.1; 2; 3; 4.121-97. Количественный химический анализ вод. Методика выполнения измерений рН в водах потенциометрическим методом. [Электронный ресурс] / Режим доступа: http://www.internet-law.ru/ stroyka/text/44486.

12. Сан ПиН 2.1.4.559-96 Питьевая вода. Гигиенические требования к качеству воды централизованных систем питьевого водоснабжения. Контроль качеств. [Электронный ресурс] / Режим доступа: http://www.internet-law.ru/ stroyka/text/9742

○ Алиева Камилла Гаджимурадовна ( kamilla.1974@mail.ru ), Даниялова Патимат Митхатовна (zoom_zoom_2213@mail.ru ),

Абдулмуталимова Тамила Омариевна ( tamila4@mail.ru ), Магомедов Абдурахман Маллаевич ( abdurahman57@mail.ru ),

Зайнудинова Асият Изамутдиновна ( asiyat232001@icloud.com ), Насрулаева Равзанат Афендиевна ( nasrulaeva_r@mail.ru ).

Журнал «Современная наука: актуальные проблемы теории и практики»

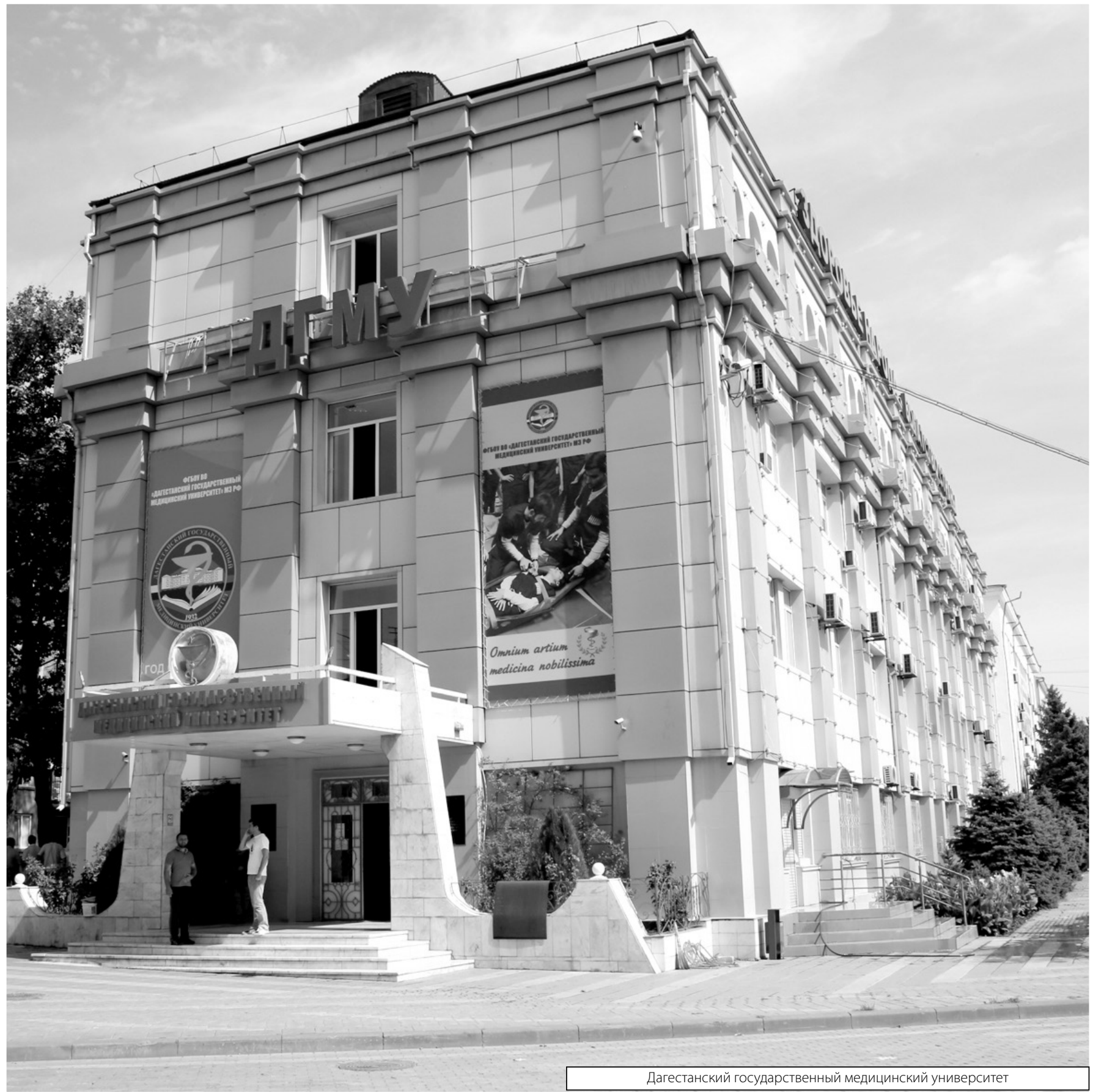

